\title{
The autophagy-related protein beclin 1 shows reduced expression in early Alzheimer disease and regulates amyloid $\beta$ accumulation in mice
}

\author{
Fiona Pickford,1 Eliezer Masliah,2 Markus Britschgi,, ${ }^{1}$ Kurt Lucin,1 Ramya Narasimhan,1 \\ Philipp A. Jaeger, ${ }^{1,3}$ Scott Small, ${ }^{4}$ Brian Spencer, ${ }^{2}$ Edward Rockenstein, ${ }^{2}$ \\ Beth Levine, ${ }^{5}$ and Tony Wyss-Coray ${ }^{1,6}$

\begin{abstract}
${ }^{1}$ Department of Neurology and Neurological Sciences, Stanford University School of Medicine, Stanford, California, USA. 2Department of Neurosciences and Pathology, UCSD, La Jolla, California, USA. ${ }^{3}$ nstitut fuer Chemie und Biochemie, Freie Universitaet Berlin, Berlin, Germany. ${ }^{4}$ Columbia University College of Physicians and Surgeons, New York, New York, USA. ${ }^{5}$ Division of Infectious Diseases,
\end{abstract} \\ University of Texas Southwestern Medical Center, Dallas, Texas, USA. ${ }^{6}$ Geriatric Research Education and Clinical Center,
} VA Palo Alto Health Care System, Palo Alto, California, USA.

\begin{abstract}
Autophagy is the principal cellular pathway for degradation of long-lived proteins and organelles and regulates cell fate in response to stress. Recently, autophagy has been implicated in neurodegeneration, but whether it is detrimental or protective remains unclear. Here we report that beclin 1, a protein with a key role in autophagy, was decreased in affected brain regions of patients with Alzheimer disease (AD) early in the disease process. Heterozygous deletion of beclin 1 (Becn1) in mice decreased neuronal autophagy and resulted in neurodegeneration and disruption of lysosomes. In transgenic mice that express human amyloid precursor protein (APP), a model for AD, genetic reduction of Becn1 expression increased intraneuronal amyloid $\beta(A \beta)$ accumulation, extracellular $A \beta$ deposition, and neurodegeneration and caused microglial changes and profound neuronal ultrastructural abnormalities. Administration of a lentiviral vector expressing beclin 1 reduced both intracellular and extracellular amyloid pathology in APP transgenic mice. We conclude that beclin 1 deficiency disrupts neuronal autophagy, modulates APP metabolism, and promotes neurodegeneration in mice and that increasing beclin 1 levels may have therapeutic potential in AD.
\end{abstract}

\section{Introduction}

Familial Alzheimer disease (AD) mutations increase the toxicity and amyloidogenicity of the amyloid $\beta(\mathrm{A} \beta)$ peptide, placing disruption of amyloid precursor protein (APP) metabolism and A $\beta$ production at the center of $\mathrm{AD}$ pathogenesis (1). However, less than $2 \%$ of $\mathrm{AD}$ cases are caused by autosomal-dominant mutations. Familial AD caused by these mutations and the remaining nondominant sporadic AD cases are pathologically similar. Therefore, factors that disrupt APP metabolism and A $\beta$ production, such as increased APP transcription, increased production of amyloidogenic A $\beta$ (2), and decreased APP degradation, may contribute to the pathogenesis of sporadic AD as well.

The etiology of $\mathrm{AD}$ is distinct from that of other neurodegenerative diseases, such as Parkinson disease and Huntington disease (HD), but all are characterized pathologically by the presence of abnormal protein aggregates and neuronal death $(3,4)$. Protein aggregates may form by abnormal folding or proteolytic processing of proteins or by the disturbance of intracellular protein degradation pathways $(3,5)$. Autophagy is involved in the intracellular degradation of aggregation-prone $\alpha$-synuclein (6) and huntingtin

Nonstandard abbreviations used: $\mathrm{A} \beta$, amyloid $\beta ; \mathrm{AD}$, Alzheimer disease; $\mathrm{APP}$, amyloid precursor protein; HD, Huntington disease; Iba-1, ionized calcium-binding associated protein-1; LC3, microtubule-associated protein 1 light chain 3; MAP-2, microtubule-associated protein 2; MCI, mild cognitive impairment; NSE, neuronspecific enolase.

Conflict of interest: The authors have declared that no conflict of interest exists. Citation for this article: J. Clin. Invest. 118:2190-2199 (2008). doi:10.1172/JCI33585
$(7,8)$. Autophagic vacuoles have previously been identified in dystrophic neurites in $\mathrm{AD}$ brains and may be a site for $\mathrm{A} \beta$ production $(9,10)$. In parallel, elimination of basal neuronal autophagy is sufficient to cause neurodegeneration in the absence of other insults $(11,12)$. Therefore, we were interested in identifying if and how autophagy is involved in the pathogenesis of AD.

Autophagy is the major pathway involved in degradation of longlived proteins and organelles, cellular remodeling, and survival during nutrient starvation $(5,13)$. A cup-shaped isolation membrane forms around cytosolic components, eventually fusing to form a double membrane-bound vesicle. This autophagosome undergoes several microtubule-dependent maturation events, including fusion with endosomes and multilamellar vesicles, before fusion with lysosomes $(14,15)$. Beclin 1 has a key role in autophagy (16-20), regulates the autophagy-promoting activity of $\operatorname{Vps} 34$ (21), and is involved in the recruitment of membranes to form autophagosomes. Beclin 1 also interacts with Bcl-2 (22), and may thus be involved in regulating cell death, but beclin 1-independent forms of autophagy may exist as well (23). BECN1 mRNA and protein are expressed in neurons and glia in human and mouse brains $(22,24)$. Whereas knockout mice lacking Becn1 (Becn1 $\left.1^{-/}\right)$die during embryogenesis $(17,18), B e c n 1^{+/-}$mice are viable; they have reduced autophagosome formation in skeletal muscle, bronchial epithelial cells, and B lymphocytes (17). However, to our knowledge, the neuronal phenotype of these mice has not previously been characterized.

We report here that beclin 1 was strongly reduced in the brains of AD patients. Beclin 1 deficiency in APP transgenic mice reduced 
A
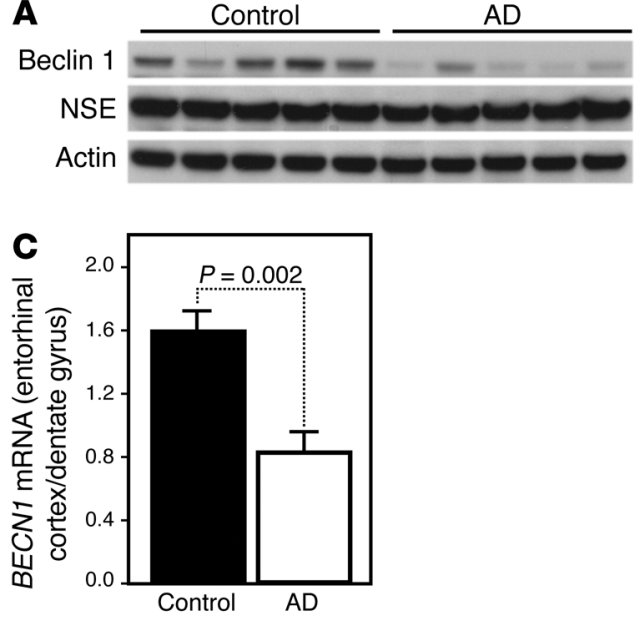

D

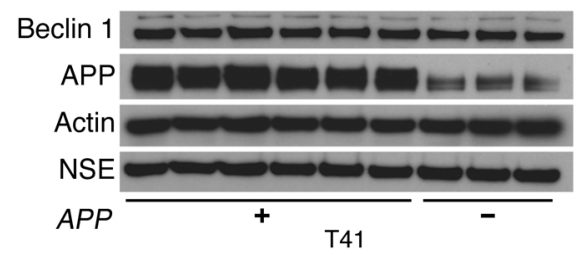

B
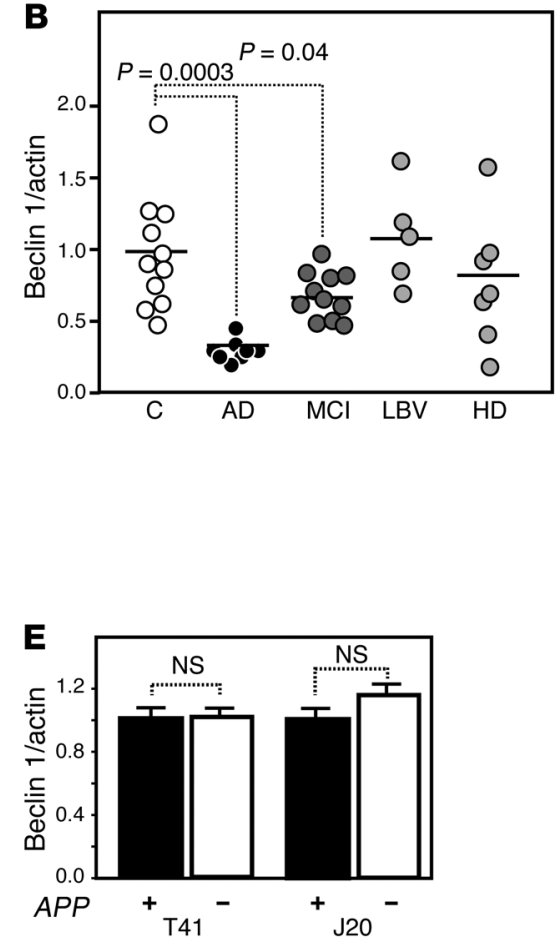

Figure 1

Beclin 1 is decreased in AD. (A and B) Levels of beclin 1 in gray matter from the midfrontal cortex of autopsy-confirmed brains of patients with $\mathrm{AD}(n=8), \mathrm{MCl}(n=11)$, Lewy body variants of AD (LBV; $n=5), \mathrm{HD}(n=7)$, and age-matched, nondemented, nonpathological controls (C; $n=11)$. (A) Representative Western blot was probed with anti-beclin 1, anti-NSE, and anti-actin antibodies. (B) Beclin 1 bands were normalized to actin and NSE controls (not shown). Each point represents 1 sample. (C) Ratios of BECN1 mRNA in the entorhinal cortex compared with dentate gyrus in control and AD patients. ( $D$ and E) Beclin 1 and APP levels in the cortex of 24-month-old T41 mice $(n=6$ APP transgenic, 3 nontransgenic) and 34-month-old J20 mice ( $n=5$ APP transgenic, 4 nontransgenic). APP expression and $A \beta$ deposition did not reduce beclin 1 levels. Values are mean $\pm S E M$; mean differences were compared by ANOVA and Dunnett's test (B) or unpaired Student's $t$ test (C and $\mathbf{E})$.

neuronal autophagy, disrupted lysosomes, promoted intracellular and extracellular $\mathrm{A} \beta$ accumulation, and resulted in neurodegeneration. Locally increasing beclin 1 expression reduced amyloid pathology in APP transgenic mice. Our data provide what we believe to be the first evidence that an essential component of the autophagy pathway is reduced in a major neurodegenerative disease and reveal a potential novel therapeutic approach for $\mathrm{AD}$.

\section{Results}

Beclin 1 is reduced in brains of $A D$ patients. To identify whether autophagy - specifically the autophagy-inducing protein beclin $1-$ is involved in $\mathrm{AD}$, we measured beclin 1 protein levels in midfrontal cortex gray matter from 8 moderate to severe $\mathrm{AD}$ cases (mean age, $81.6 \pm 4.2$ years; mini-mental state examination [MMSE] score, $<14$ ), 11 cases of mild cognitive impairment (MCI; mean age, $85.1 \pm 2.7$ years; MMSE score, >26) and 11 nondemented controls (mean age, $77.2 \pm 2.3$ years) (Figure 1, A and B, and Supplemental Table 1; supplemental material available online with this article; doi:10.1172/ JCI33585DS1). The clinical diagnosis of patients with amnestic $\mathrm{MCI}$, which can be considered an early, prodromal form of $\mathrm{AD}(25)$, was confirmed by the presence of mild $\mathrm{AD}$ pathology postmortem (data not shown). In these $\mathrm{MCI}$ cases, beclin 1 levels were reduced to to microarray and identified mRNAs

$70 \%$ of the level detected in age-matched controls, and in severe $\mathrm{AD}$, beclin 1 levels were reduced to $30 \%$ of control levels. In contrast, beclin 1 levels were not significantly decreased in patients affected with Lewy body variant of AD (Figure 1B). Interestingly, cases with $\mathrm{HD}$ had no significant overall reduction in beclin 1 levels, although individual cases showed reductions in the range of $\mathrm{AD}$.

Beclin 1 levels were not reduced in gray matter from the unaffected cerebellum of $8 \mathrm{AD}$ cases compared with 8 age-matched controls (relative beclin 1 , AD, 0.900; control, 0.963; $P=0.8$; mean age, $\mathrm{AD}, 79.4 \pm 3.2$ years; control, $72.9 \pm 4.3$ years). Beclin 1 levels were independent of postmortem interval, age, or sex. Immunohistochemical analysis showed beclin 1 immunoreactivity in cortical human neurons. With advancing $\mathrm{AD}$, both overall beclin 1 immunoreactivity and the number of positive cells decreased (Supplemental Figure 1). Although immunostaining in human postmortem brain sections can be difficult to verify, the staining seemed consistent with the panneuronal BECN1 mRNA expression pattern in mice reported in the Allen Brain Atlas (24). Others have also reported that beclin 1 is expressed in both neurons and glia $(8,22,26)$.

Beclin 1 was also reduced in $\mathrm{AD}$ brains at the mRNA level. We relied on the spatiotemporal profile of $\mathrm{AD}(27)$ to address analytic limitations inherent differentially expressed in $\mathrm{AD}$ brains versus controls (28). Using a previously generated microarray dataset (28), we divided mRNA levels in the vulnerable entorhinal cortex by mRNA levels in the relatively protected dentate gyrus to control for interindividual variation. A 50\% reduction in BECN1 mRNA was observed in $\mathrm{AD}$ cases compared with controls (Figure 1C).

In summary, beclin 1 levels were specifically reduced in $\mathrm{AD}$ brains in the entorhinal cortex. Because levels of the neuronal protein neuron-specific enolase (NSE) were not significantly reduced in any condition compared with nondemented controls (Figure 1A), it is unlikely that the reduction in beclin 1 is entirely attributable to neuronal cell loss. On the other hand, the immunohistochemistry showed fewer beclin 1-immunopositive cells in the advanced stages of $\mathrm{AD}$, and it is likely that neuronal loss contributed to the decrease in beclin 1 as well.

AD-like pathology in transgenic mice does not cause beclin 1 deficiency. The reduction of beclin 1 in affected regions of AD brains (Figure $1, \mathrm{~A}-\mathrm{C}$ ) could cause or contribute to the development of $\mathrm{AD}$, could be unrelated, or could be a result of AD pathology. To investigate this question, we analyzed cortical beclin 1 protein levels in 2 different lines of very old APP transgenic mice (J20, 34 months old; T41, 24 months old; see Methods). Both lines 
A

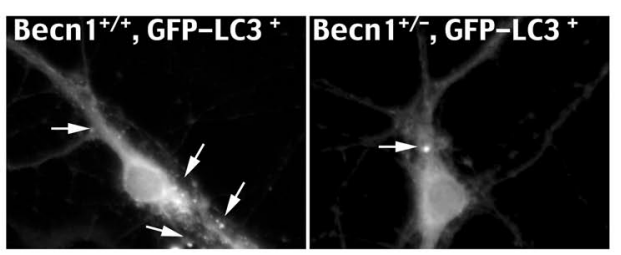

C

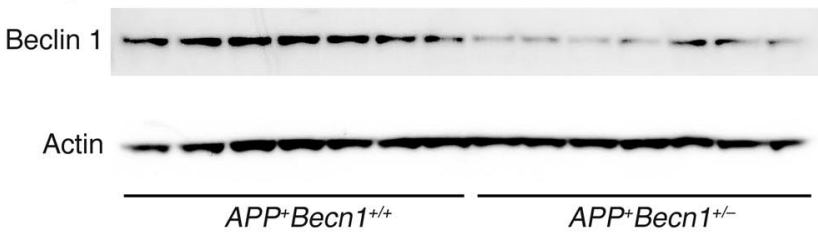

E
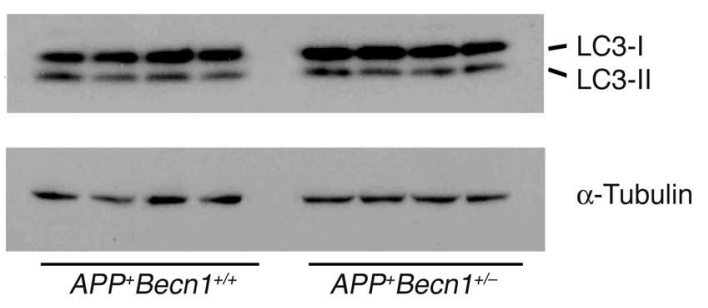

express high levels of mutant human APP and develop extensive $\mathrm{A} \beta$ deposits $(29,30)$, thus reproducing key aspects of $\mathrm{AD}$ pathology. Beclin 1 levels were not reduced in either T41 or J20 mice compared with nontransgenic, age-matched littermate control mice (Figure 1, D and E). These data demonstrate that overproduction of mutant APP and development of amyloid pathology was not sufficient to cause beclin 1 deficiency in mice and leave the possibility that the reduction in beclin 1 observed in $\mathrm{AD}$ cases occurs upstream of APP pathology.

Becn $1^{+/-}$mice have reduced neuronal autophagy. Beclin 1 has a key role in autophagy and is involved in the formation of autophagosomes in peripheral cells (16). To determine whether reduced beclin 1 levels affect autophagosome formation in neurons, we crossed Becn $1^{+/}$mice with transgenic mice that systemically express a GFP-tagged microtubule-associated protein 1 light chain 3 (GFP-LC3) fusion protein under the control of a chicken $\beta$-actin promoter (31). Because LC3 is a marker for autophagosomes (32), we were able to count autophagosomes marked by GFP-LC3-dot formation in cultured primary hippocampal neurons from GFP$\mathrm{LC}^{+} \mathrm{Becn}^{+/+}$and $\mathrm{GFP}-\mathrm{LC} 3^{+} \mathrm{Becn} 1^{+/-}$mice (Figure 2A). Neurons with wild-type beclin 1 expression showed numerous autophagosomes. Beclin 1-deficient neurons had fewer than half the number of autophagosomes (Figure 2, A and B), indicating reduced neuronal autophagy. These data are consistent with reports of reduced autophagy in peripheral tissues of these mice (17).

Beclin 1 deficiency promotes extracellular and intraneuronal $A \beta$ deposition in APP transgenic mice. To study the role of Becn1 deficiency on amyloid pathology in a model of AD, Becn $1^{+/-}$mice (17) were crossed with the above-described T41 APP heterozygous transgenic mice, which develop progressive AD-like amyloid pathology starting in the frontal cortex at 3-5 months of age (30). As expected, beclin 1 protein levels were reduced by half in $A P P^{+} B e c n 1^{+/-}$mice
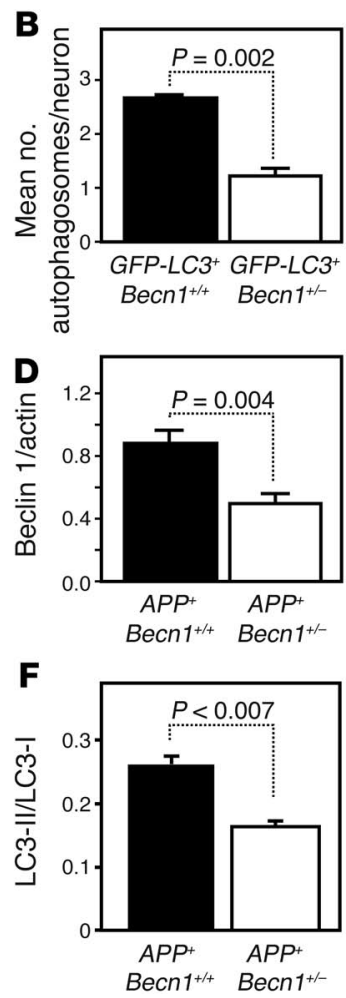

\section{Figure 2}

Beclin 1 and neuronal autophagy are reduced in Becn1+/- mice. (A and $\mathbf{B}$ ) Autophagosomes (arrows) were counted in 50 primary hippocampal neurons cultured from GFP-LC3+Becn1+/+ and GFP$L C 3^{+} B e C n 1^{+/-}$mice ( $n=3$ per group). Shown are representative images (A) and quantification (B). (C and D) RIPA buffer-soluble proteins from the cortex of 9-month-old female $A P P^{+} B e c n 1^{+/-}$and

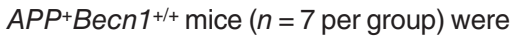
analyzed by Western blot and probed for beclin 1; values were normalized to actin levels. (E and F) RIPA buffer-soluble proteins from the cortex of 16-month-old male $A P P^{+} B e c n 1^{+/-}$and $A P P^{+} B e c n 1^{+/+}$mice ( $n=4$ per group) were analyzed by Western blot and probed for LC3; values were normalized to $\alpha$-tubulin levels, and the ratio between LC3-I and LC3-II was calculated. Values are mean \pm SEM; mean differences were compared by unpaired Student's $t$ test. Original magnification, $\times 400$. compared with $A P P^{+} B e c n 1^{+++}$littermates at both 9 (Figure 2, C and D) and 3.5 months of age (data not shown). This deficiency in beclin 1 was associated with reduced autophagy, as demonstrated by a decrease in the relative levels of LC3-II compared with LC3-I (Figure 2, E and F). While LC3-I is present in the cytosol, the lipidated LC3-II form is associated mainly with autophagosomal membranes, serving as a good indicator of autophagosomes (32, 33). These data are consistent with reduced neuronal autophagy in GFP-LC3 $3^{+} \mathrm{BeCn}^{1^{+/-}}$mice (Figure 2, A and B).

Beclin 1 deficiency and reduced autophagy were accompanied by a nearly 2-fold increase in extracellular $A \beta$-immunoreactive deposits in 9-month-old female $A P P^{+} B e c n 1^{+/}$mice compared with $A P P^{+} B e c n 1^{1^{++}}$ littermate controls (Figure 3, A and B). A $\beta$ deposition is accelerated in female compared with male T41 mice; therefore, we analyzed only females here. In agreement with the $A \beta$ results, the number of thioflavin S-positive plaques (extracellular fibrillar amyloid) with globular shapes increased 3-fold in $A P P^{+} B e{ }^{+1 /-}$ mice compared with $A P P^{+} B e c n 1^{+/+}$mice $\left(A P P^{+} B e c n 1^{+/+}, 0.5 \pm 0.15 ; A P P^{+} B e c n 1^{+/-}\right.$, $1.88 \pm 0.3 ; n=7-8$ per genotype; $P=0.002$ ). In addition, intraneuronal $\mathrm{A} \beta$ was increased in $A P P^{+} B e c n 1^{+/-}$mice (Figure 3, $\mathrm{C}$ and $\mathrm{D}$ ) in both the frontoparietal cortex and the hippocampus. The role of intracellular $\mathrm{A} \beta$ in $\mathrm{AD}$ is unclear, but evidence from neuropathological studies in humans suggests that it accumulates early in the disease process, a finding that has been replicated in some $\mathrm{AD}$ mouse models (reviewed in ref. 34). In T41 mice, we found prominent intracellular A $\beta$ that increased with age while APP levels remained constant (Supplemental Figures 3 and 4). Interestingly, intraneuronal $A \beta$ colocalized in part with cathepsin D (Supplemental Figure 4), a marker for lysosomes and mature autophagosomes (35).

In support of these histological data, levels of formic acid-soluble $\mathrm{A} \beta_{1-\mathrm{x}}$ measured by ELISA in $A P P^{+} B e c n 1^{+/-}$mice more than doubled compared with $A P P^{+} B e c n 1^{+/+}$mice in the neocortex (Figure $3 \mathrm{E}$ ) and 

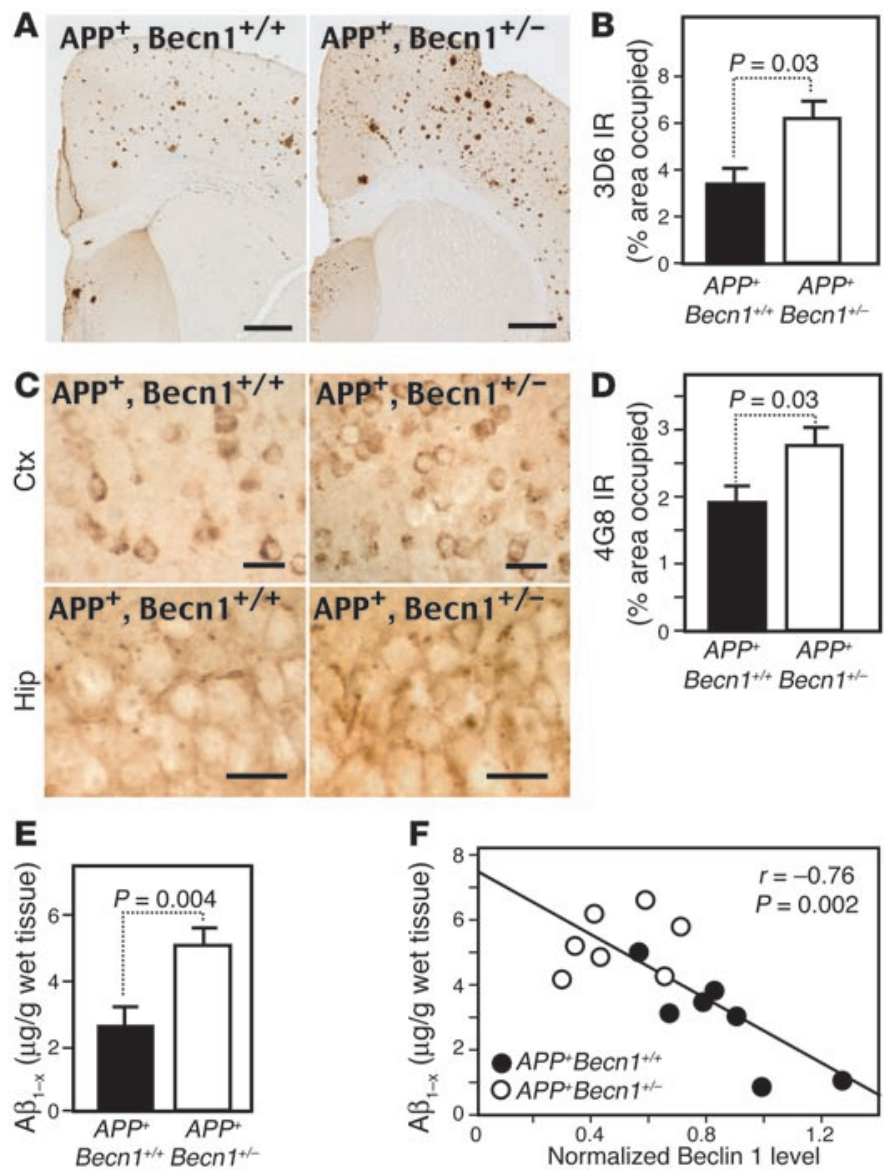

significantly increased in the hippocampus (Table 1). Trends for increased formic acid soluble $\mathrm{A} \beta_{1-42}$ were also seen in $\mathrm{APP} B e c n 1^{+/-}$ mice (Table 1). Importantly, levels of formic acid-soluble $A \beta$ in these mice correlated inversely with beclin 1 protein levels in the neocortex (Figure 3F), further linking reduced beclin 1 levels with increased $A \beta$ deposition. Beclin 1 deficiency did not result in significant differences in APP or the C-terminal fragments of APP (APP-CTF) steady-state levels or formic acid extractable $A \beta$ levels in young mice, although a trend toward increased total A $\beta$ levels was noted (Table 1 and Supplemental Figure 2). Together, these data show that beclin 1 deficiency in young mice does not prominently alter APP processing or turnover.

Beclin 1 deficiency results in microglial changes in APP transgenic mice. Microglia in the brain are a sensitive indicator of brain injury, and we sought to determine whether these cells show abnormal activation or changes in response to increased $A \beta$ accumulation associated with beclin 1 deficiency. Relative expression of microglial CD68 in the neocortex of female $A P P^{+} B e c n 1^{+/-}$mice increased 2.5 -fold compared with $A P P^{+} B e c n 1^{+/+}$littermates and was clustered around $\mathrm{A} \beta$ deposits (Figure $4, \mathrm{~A}$ and $\mathrm{B}$ ). CD68, or macrosialin, is a heavily glycosylated transmembrane protein expressed in late endosomes and - to a smaller extent - on the cell surface of myeloid cells. Increased CD68 expression has previously been used to indicate activation or increased phagocytic activity of macrophages and microglia $(36,37)$. On the other hand, expression of ion-

\section{Figure 3}

$A P P^{+} B e c n 1^{+/-}$mice have increased amyloid pathology. (A and $\mathbf{B}$ ) $A \beta$ immunoreactivity in the frontal cortex of 9-month-old female $A P P+B e c n 1^{+/-}$and $A P P+B e c n 1^{+/+}$mice. Coronal brain sections were immunostained with biotinylated anti-A $\beta_{1-5}$ antibody (3D6). A $\beta$ deposition was defined by the percent area of $A \beta$ immunoreactivity (IR). (C and D) Intracellular $A \beta$ immunoreactivity (4G8) in the hippocampus (Hip) and frontoparietal cortex (Ctx) of 9-month-old female $A P P^{+} B e c n 1^{+/-}$and $A P P^{+} B e c n 1^{+/+}$mice. (E) Total formic acid-soluble $A \beta_{1-x}$ levels measured by ELISA in the neocortex of female $A P P^{+} B e c n 1^{+/-}$and $A P P+B e c n 1^{+/+}$mice. (F) Total formic acid-soluble $A \beta_{1-x}$ levels were inversely correlated with relative beclin 1 protein levels in the cortex. Values are mean \pm SEM; mean differences were compared by unpaired Student's $t$ test. $n=7-8$ per genotype. Scale bars: $100 \mu \mathrm{m}(\mathbf{A}) ; 10 \mu \mathrm{m}$ (C). ized calcium-binding associated protein-1 (Iba-1), another macrophage/microglia marker with unknown function, was not changed by beclin 1 deficiency in APP mice (Figure 4, A and C). The increase in CD68 expression of microglia clustered around $A \beta$ deposits in the absence of changes in Iba- 1 expression indicates that beclin 1 deficiency alters the microglial response to $A \beta$.

Beclin 1 deficiency promotes synaptodendritic degeneration and results in neuronal loss in APP mice. Synaptic degeneration occurs early in AD pathogenesis (38-41), and complete knockout of 2 essential autoph-

\section{Table 1}

Effect of beclin 1 deficiency on cerebral $A \beta$ accumulation in APP transgenic mice

\begin{tabular}{|c|c|c|c|c|c|}
\hline $\begin{array}{l}\text { Age } \\
(\mathrm{mo})\end{array}$ & Brain region & Genotype & $n$ & $\begin{array}{l}\text { Formic acid } \\
A \beta_{1-x}(n g / g)\end{array}$ & $\begin{array}{l}\text { Formic acid } \\
A \beta_{1-42}(\mathrm{ng} / \mathrm{g})\end{array}$ \\
\hline $\begin{array}{l}3.5 \\
3.5\end{array}$ & $\begin{array}{l}\text { Neocortex } \\
\text { Neocortex }\end{array}$ & $\begin{array}{l}\text { APP+Becn1+/+ } \\
\text { APP+Becn1+/- }\end{array}$ & $\begin{array}{l}3-5 \\
3-5\end{array}$ & $\begin{array}{l}10.7 \pm 0.5 \\
18.1 \pm 5.2\end{array}$ & $\begin{array}{r}10.5 \pm 6.5 \\
8.7 \pm 3.8\end{array}$ \\
\hline $\begin{array}{l}9 \\
9\end{array}$ & $\begin{array}{l}\text { Neocortex } \\
\text { Neocortex }\end{array}$ & $\begin{array}{l}\text { APP+Becn1+/+ } \\
\text { APP+Becn1+/- }\end{array}$ & $\begin{array}{l}6-8 \\
6-8\end{array}$ & $\begin{array}{l}25,351 \pm 6,010 \\
52,530 \pm 3,537^{A}\end{array}$ & $\begin{array}{l}2,833 \pm 700 \\
4,275 \pm 423\end{array}$ \\
\hline $\begin{array}{l}3.5 \\
3.5\end{array}$ & $\begin{array}{l}\text { Hippocampus } \\
\text { Hippocampus }\end{array}$ & $\begin{array}{l}\text { APP+Becn1+++ } \\
\text { APP+Becn1+- }\end{array}$ & $\begin{array}{l}3-5 \\
3-5\end{array}$ & $\begin{array}{l}35.4 \pm 11.6 \\
53.8 \pm 18.8\end{array}$ & $\begin{array}{l}11.8 \pm 7.8 \\
14.1 \pm 5.1\end{array}$ \\
\hline $\begin{array}{l}9 \\
9\end{array}$ & $\begin{array}{l}\text { Hippocampus } \\
\text { Hippocampus }\end{array}$ & $\begin{array}{l}\text { APP+Becn1+/+ } \\
\text { APP+Becn1+1- }\end{array}$ & $\begin{array}{l}6-8 \\
6-8\end{array}$ & $\begin{array}{l}32,834 \pm 6,108 \\
48,646 \pm 3,844^{B}\end{array}$ & $\begin{array}{l}2,599 \pm 643 \\
5,110 \pm 1,043^{c}\end{array}$ \\
\hline
\end{tabular}

Values are mean \pm SEM. ${ }^{A} P<0.005 ;{ }^{B} P<0.05 ; C P<0.10$ versus age-matched littermate control mice (unpaired Student's $t$ test). 
A

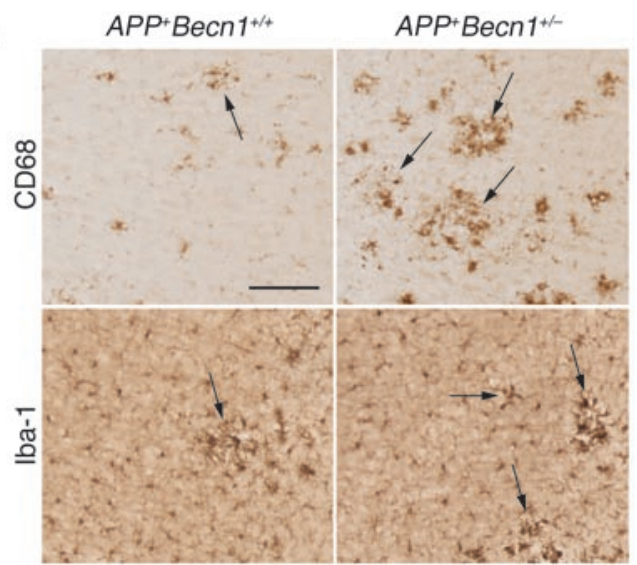

B

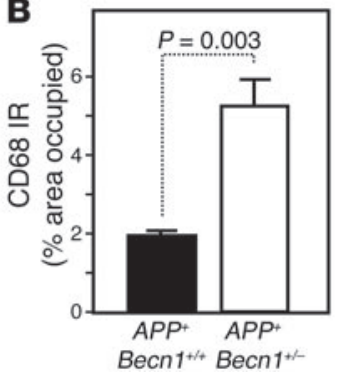

C

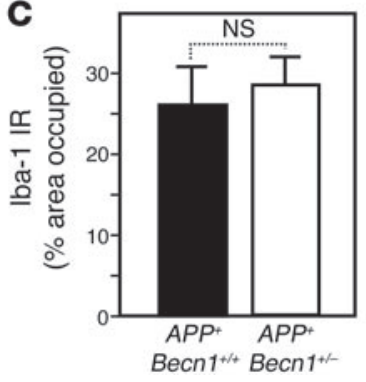

agy genes $(\operatorname{Atg} 5$ or $\operatorname{Atg} 7)$ in neurons resulted in accumulation of ubiquitinated proteins and neuronal loss $(11,12)$. We hypothesized that beclin 1 deficiency, similar to that observed in $\mathrm{AD}$, would promote neurodegeneration in transgenic mouse models of AD. Indeed, beclin 1 deficiency in 9-month-old $A P P^{+} B e c n 1^{+/-}$mice resulted in a significant reduction of synaptophysin-immunoreactive synaptic terminals in

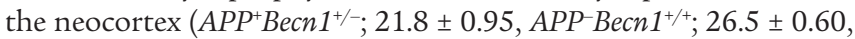
$P=0.0003$; Figure 5A) and hippocampus (Figure 5B) compared with wild-type littermate controls. Similarly, expression of the dendritic marker microtubule-associated protein 2 (MAP-2) was significantly reduced in $\mathrm{APP}^{+} \mathrm{Becn} 1^{+/-}$mice compared with wild-type littermate controls (Figure 5, C and D). In wild-type mice, strong MAP-2 immunoreactivity was detected both in soma and in neuronal processes, whereas in $\mathrm{APP}^{+} \mathrm{BeCn} 1^{+/-}$mice the immunoreactivity in neuronal processes was disrupted. These markers of synaptodendritic integrity have been used as sensitive, early indicators of neuronal degeneration in $\mathrm{AD}$ and various mouse models of the disease (29, 42-45). A similar decrease in calbindin immunoreactivity, which was previously shown to correlate closely with APP-associated memory deficits in APP mice (46), was also observed in $A P P^{+} B e c n 1^{+/-}$mice (Figure 5E). Notably, beclin 1 deficiency alone in $A P P^{-} B e c n 1^{+/-}$mice resulted in a significant decrease in all 3 markers.

Intriguingly, beclin 1 deficiency resulted in a significant loss of neurons in layer II of the entorhinal cortex in $\mathrm{APP}^{+} \mathrm{Becn} 1^{+/-} \mathrm{com}-$ pared with wild-type or $A P P^{-} B e c n 1^{+/-}$mice (Figure $5 \mathrm{~F}$ ). In line with other studies (47), $A P P^{+} B e c n 1^{+/+}$mice showed no significant loss of neurons; similarly, $A P P^{-} B e c n 1^{+/-}$mice had no significant loss (Figure $5 \mathrm{~F}$ ). There was no gross difference in the size of the hippocampus or frontal cortex in $A P P^{+} B e c n 1^{+/+}$or $A P P^{+} B e c n 1^{+/-}$mice (Supplemental Table 2). Together, these findings demonstrate that beclin 1 deficiency is sufficient to cause synaptic degeneration in the absence of human APP overexpression and that beclin 1 is required for maintaining neuronal integrity.

\section{Figure 4}

Microglial changes in $A P P^{+} B e c n 1^{+/-}$mice. (A-C) Microglial changes in the frontal cortex of 9-month-old female $A P P^{+} B e c n 1^{+/-}$and $A P P+B e c n 1^{+/+}$ mice assessed by immunostaining with antibodies against CD68 and Iba-1. Shown are representative images (A) and quantification (B and C). Arrows denote microglial clusters around amyloid deposits. Values are mean \pm SEM; mean differences were compared by unpaired Student's $t$ test. $n=7-8$ per genotype. Scale bar: $50 \mu \mathrm{m}$.

Disrupted lysosomes in $A P P^{+} B e c n 1^{+/-}$mice. To gain further insight into the pathological changes caused by beclin 1 deficiency in the brain, the ultrastructure of neurons in 5-month-old $\mathrm{APP}^{+} \mathrm{Becn} 1^{+/-}$ mice was examined by electron microscopy (Figure 6 and Supplemental Figure 5). Beclin 1 deficiency led to a striking accumulation of abnormal, enlarged lysosomes with electron-dense material (Figure 6). While this was evident in $A P P^{-} B e c n 1^{+/-}$mice, it was much more pronounced in the context of APP and $A \beta$ overproduction in $A P P^{+} B e c n 1^{+/-}$mice, highlighting a potential synergism between the 2 genetic alterations. As previously reported, APP transgenic mice (i.e., $A P P^{+} B e c n 1^{+/+}$) show multilaminated dense core bodies, some of which may be autophagosomes, in dystrophic neurites (35). However, these mice did not show the prominent lysosomal abnormalities we observed in $A P P^{+} B e c n 1^{+/-}$mice. In addition, $A P P^{+} B e c n 1^{+/-}$mice showed an accumulation of lamellar bodies in synapses, autophagosome-like laminar bodies, and an accumulation of fibrils and electron-dense bodies in axons (Supplemental Figure 5). These ultrastructural changes support the synaptodendritic abnormalities documented by immunohistochemistry (Figure 5).

Beclin 1 overexpression reduces intracellular and extracellular $A \beta$. To determine whether increasing beclin 1 levels could reduce AD-like pathology, 6-month-old APP transgenic mice were injected in the frontal cortex and hippocampus with lentivirus encoding mouse beclin 1 (right hemibrain) or GFP (left hemibrain, internal control). After 8 weeks, GFP and mouse beclin 1 were expressed prominently (Figure 7A). Hemibrains expressing mouse beclin 1 had significantly less intracellular $A \beta$ immunoreactivity than did their respective GFPexpressing hemibrains (Figure 7, B and C). In addition, extracellular $\mathrm{A} \beta$ deposition, as assessed by thioflavin $\mathrm{S}$ in the frontal cortex, was also reduced by mouse beclin 1 expression (Figure 7D).

\section{Discussion}

Our data implicate beclin 1 and autophagy in AD pathogenesis. They suggest that beclin 1 deficiency, which was observed in AD but not in related dementias, can promote neurodegeneration and accelerate $A \beta$ accumulation. Beclin 1 levels were reduced early in $A D$ in the affected midfrontal cortex (Figure 1, A and B), but were not reduced in the largely unaffected cerebellum, even at late stages of the disease. Beclin 1 levels were reduced equally whether they were compared with actin levels or with the neuronal marker NSE, indicating that the relative amount of beclin 1 per neuron is reduced. However, immunohistochemistry also showed that both the number of neurons and the relative intensity of staining decreased with advancing disease, making it likely that beclin 1 levels decrease both as a consequence of reduced expression overall and as a result of neuronal loss. There was no decrease in beclin 1 in the midfrontal cortex from patients with the related Lewy body variant of $A D$, suggesting that the prominent decrease in beclin 1 has specificity to the most common form of AD. In the context of recent studies implicating autophagy in $\operatorname{HD}(7,8)$ and the observation that beclin 1 is recruited to intraneuronal inclusions in this disease (8), it is inter- 


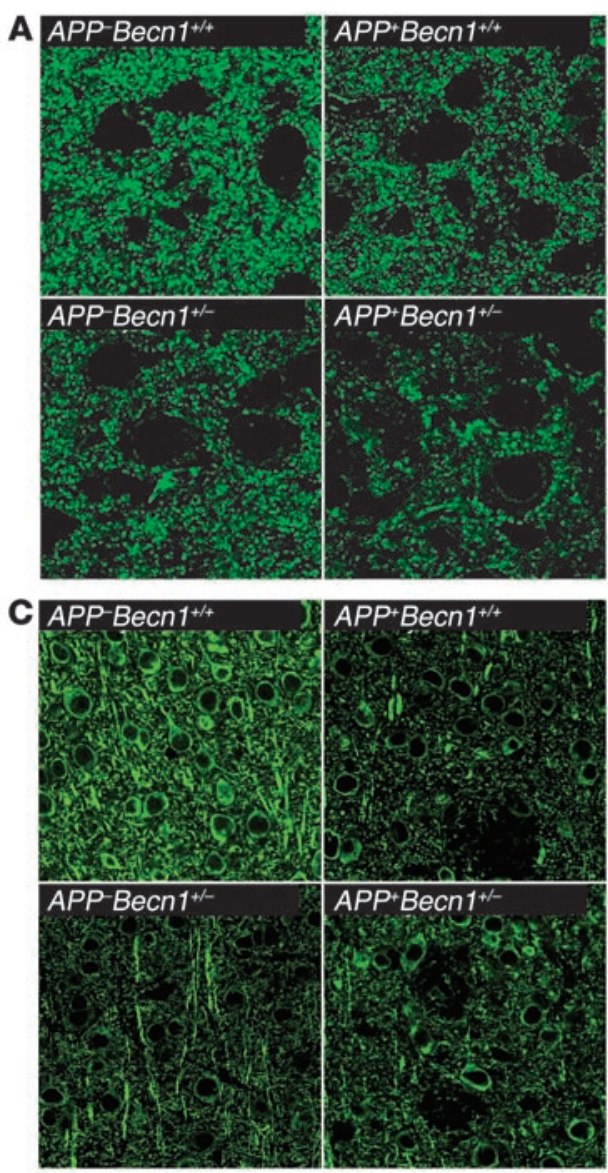

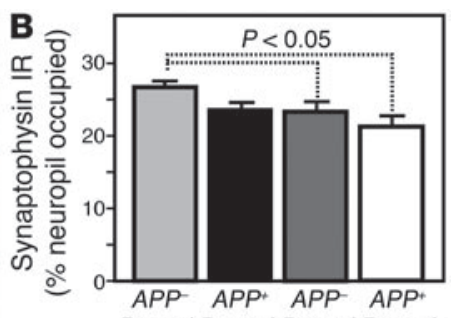

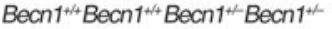

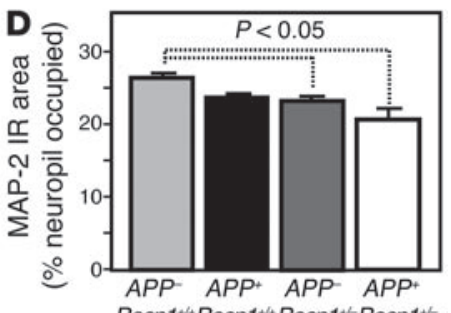

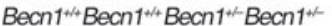

\section{Figure 5}

Neurodegeneration in 9-month-old $A P P^{+} B e c n 1^{+/-}$ mice. (A-E) Synaptophysin (A and B), MAP-2 (C and D), and calbindin (E) immunoreactivity in 9-month-old female $A P P^{+} B e c n 1^{+/-}$mice and control littermates. Brain regions analyzed are frontal cortex $(\mathbf{A}, \mathbf{C}$, and D), hippocampus (B), and dentate gyrus (E). Coronal brain sections were immunostained with the respective antibodies, and the mean percentage immunoreactive area $(\mathbf{A}-\mathbf{D})$ or OD (E; diaminobenzidine staining) per mouse was calculated and analyzed by ANOVA and Tukey-Kramer post-hoc test $(n=7-8$ per genotype). (A and $\mathbf{C}$ ) Note the disruption of synaptic and dendritic morphology in $A P P^{-} B e c n 1^{+/-}$and $A P P^{+} B e c n 1^{+/-}$mice. (F) Neuronal cell counts in layer II of the entorhinal cortex were estimated using the optical dissector method. Results were analyzed by ANOVA and Tukey-Kramer post-hoc test ( $n=3$ per genotype). Values are mean \pm SEM. Original magnification, $\times 980(\mathbf{A}) ; \times 720$ (C).
E

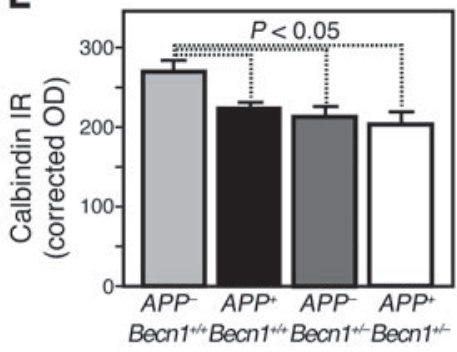

F

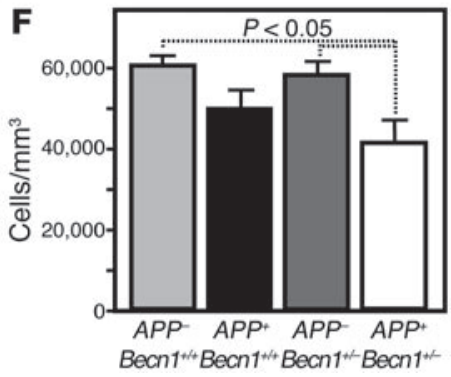

esting that some cases with HD had very low beclin 1 levels (Figure 1B). Sequestration of beclin 1 may provide a mechanism for locally reducing beclin 1 levels that may affect neuronal integrity in a manner similar to the net beclin 1 reductions described here.

It is pertinent at this point to ask whether AD pathology itself drives beclin 1 reduction, perhaps by overstimulating or exhausting the autophagy pathway. Indeed, increased numbers of autophagic vacuoles have previously been identified in dystrophic neurites in brains of humans with $\operatorname{AD}(35,48)$ and in APP transgenic mice (10, 35 ). We also found that beclin 1 levels were lower in moderate and severe $\mathrm{AD}$ than in early $\mathrm{AD}$ and/or MCI. On the other hand, BECN1 mRNA was specifically decreased in the entorhinal cortex of AD patients (Figure $1 \mathrm{C}$ and ref. 28), and BECN1 mRNA and protein levels decrease with age in the human brain independent of AD pathology (8). Moreover, beclin 1 was not reduced in 2 mouse models of AD that overexpress APP (Figure 1D). These findings showed that ADlike amyloid pathology observed in mice was not sufficient to deplete beclin 1 levels in vivo, although they do not exclude the possibility that beclin 1 is reduced in more chronically injured neurons in AD.

How beclin 1 is regulated in neurons and why it decreases with age or in $\mathrm{AD}$ is unclear at this time. Future studies will show whether other factors associated with $\mathrm{AD}$ pathology promote beclin 1 deficiency and whether individuals with low beclin 1 levels in the brain are at risk of developing neurodegeneration and AD. Bcl-2, Vps34, and the recently described protein UV irradiation resistance-associated gene (UVRAG) can all bind to beclin 1 and thereby regulate autophagy $(20,21,49-51)$. Whether these factors also affect beclin 1 transcription is not known. In addition, it is possible that beclin 1 deficiency has effects involving these or other proteins independent of autophagy. Autophagy in AD may be misregulated not only by beclin 1 deficiency, but also by disruption of axonal transport (52-54) or by dysfunction of presenilins, which are part of a $\gamma$-secretase complex and have previously been implicated in fusion of autophagosomes with lysosomes $(10,55,56)$. 


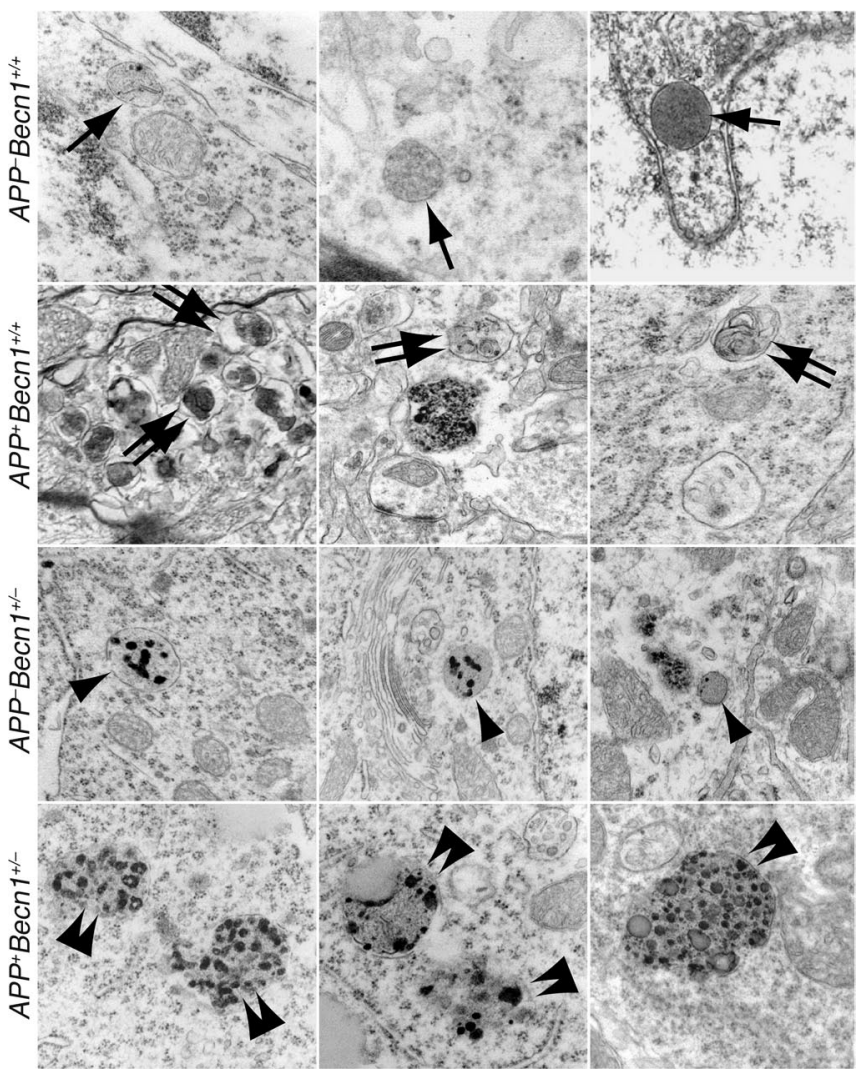

Beclin 1-deficient APP mice had higher levels of A $\beta$ than did APP mice at 9 months of age, as assessed by immunohistochemical and biochemical methods (Figure 3 and Table 1). In contrast, beclin deficiency did not change A $\beta$, APP, or APP-CTF levels significantly in young mice (Supplemental Figure 2 and Table 1) and is thus unlikely to affect processing of APP to a prominent extent. Cellular and molecular studies will be necessary to determine whether autophagy or beclin 1 have more subtle effects on APP metabolism and A $\beta$ secretase activities. The mechanism by which beclin 1 deficiency promotes $A \beta$ accumulation is of great interest. One possibility is that beclin 1 is necessary for the degradation of intracellular A $\beta$ or APP by autophagy. In support of this, we showed that autophagy was reduced in beclin 1-deficient neurons (Figure 2). Beclin 1 deficiency promoted the accumulation of $A \beta$ in neurons (Figure 3, C and D), and intracellular $\mathrm{A} \beta$ colocalized with the lysosomal hydrolase cathepsin D (Supplemental Figure 4). In addition, electron microscopy revealed that beclin 1-deficient neurons had abnormal lysosomes that contained electron-dense bodies and that these were much more prevalent and enlarged in the presence of APP. Moreover, beclin 1 overproduction by viral delivery reduced intraneuronal (and extracellular) A $\beta$ (Figure 7). Disruptions to the endosomal/lysosomal system have been consistently reported in $\mathrm{AD}$ (57); however, to our knowledge, the ultrastructural disruptions caused by beclin 1 deficiency were previously unknown. The reduction in neuronal autophagy and disruption of the lysosomes in beclin 1deficient conditions may be explained by separate actions of beclin 1 both on autophagy and on endosome/lysosome fusion (58), as found in yeast. Recent data suggest that the Vps34/beclin 1 complex may be differentially regulated by additional binding

\section{Figure 6}

Abnormal lysosomes in $A P P^{+} B e c n 1^{+/-}$mice. Electron micrographs of neurons from 5-month-old mice. APP-Becn1+/+ mice had normal lysosomes (single arrows). $A P P^{+} B e c n 1^{+/+}$mice had multilaminated dense core bodies in dystrophic neurites (double arrows). $A P P-B e c n 1^{+/-}$mice had lysosomes containing electron-dense bodies (single arrowheads). $A P P^{+} B e c n 1^{+/-}$mice had abundant enlarged lysosomes containing electron-dense bodies (double arrowheads). Original magnification, $\times 25,000$.

proteins to function in either the autophagy or endosome pathways (51). For example, UVRAG binds Vps34/beclin 1 in mammalian cells and forms several distinct complexes (51). Alternatively, beclin 1 may be directly involved only in autophagy, but disruption of the autophagy pathway may subsequently affect the flux of other intracellular organelles (e.g., endosomes), resulting in the disruption of lysosomes. This explanation is supported by evidence that beclin 1 only modulates the autophagy function of Vps34 in mammalian cells (21).

Another possibility is that beclin 1 deficiency disrupts intracellular organelle dynamics, thereby shifting the distribution of APP to different subcellular compartments that generate more $A \beta$. While APP processing occurs in many intracellular compartments, $A \beta$ is generated at high levels in the acidic endosome/lysosome system (59). The expansion of this compartment, as revealed by electron microscopy in $\mathrm{APP}^{+} \mathrm{Becn}^{+/-}$neurons (Figure 6 and Supplemental Figure 5), could result in increased $A \beta$ production. These possibilities are not mutually exclusive and may not be restricted to neurons. It is interesting to note that levels of CD68, a late endosomal marker of microglia, were strongly increased in microglia clustered around A $\beta$ deposits in beclin 1-deficient APP mice (Figure 4). It is therefore possible that these cells are also less efficient in clearing $\mathrm{A} \beta$ taken up from the extracellular milieu. Furthermore, it remains to be shown whether the primary toxic action of $A \beta$ occurs inside or outside the cell (34). Our finding that beclin 1 deficiency resulted in increased intracellular and extracellular $\mathrm{A} \beta$ accumulation provides an example of how the intracellular action (or deficiency) of a protein can affect extracellular accumulation of $A \beta$.

Beclin 1 deficiency alone, in the absence of the human APP transgene, was sufficient to cause synaptodendritic degeneration in vivo, which indicates that beclin 1 deficiency does not require $\mathrm{A} \beta$ to cause neurodegeneration. In beclin 1 -deficient mice, synaptophysin, calbindin, and MAP-2 immunoreactivities were reduced. MAP-2 distribution was disrupted (Figure 5), and lysosomes contained abnormal electron-dense granules (Figure 6). Although this did not lead to frank neuronal loss in layer II of the entorhinal cortex (Figure 5F), these data support previous reports that complete knockout of the autophagy genes Atg 5 or Atg 7 in postnatal neurons result in a neurodegenerative phenotype $(11,12)$. Our data also extend the previous findings to show that a pathologically relevant reduction in another key autophagy protein was sufficient to cause a neurodegeneration that mimicked aspects of $A D$. $\mathrm{APP}^{+} \mathrm{BeCn}^{+/-}$mice had increased synaptodendritic degeneration, and the number of neurons measured in layer II of the entorhinal cortex were significantly reduced. These data are consistent with previous reports that synaptic degeneration precedes gross neuronal loss in $\operatorname{AD}(40,41)$.

In summary, we identified beclin 1 and autophagy as important modulators of neurodegeneration and $A \beta$ accumulation in a mouse model for $\mathrm{AD}$. We also found beclin 1 was significantly 
A

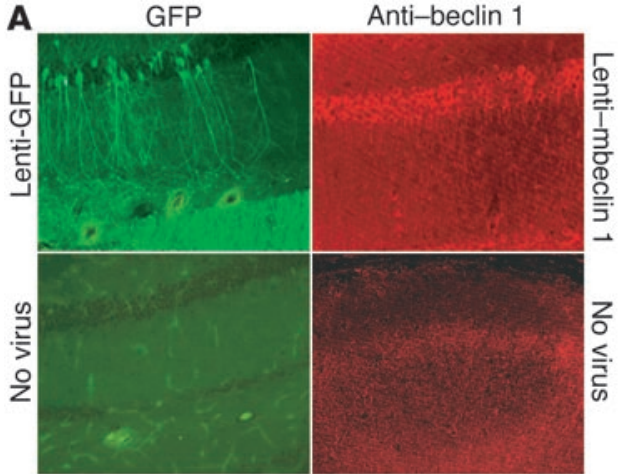

B

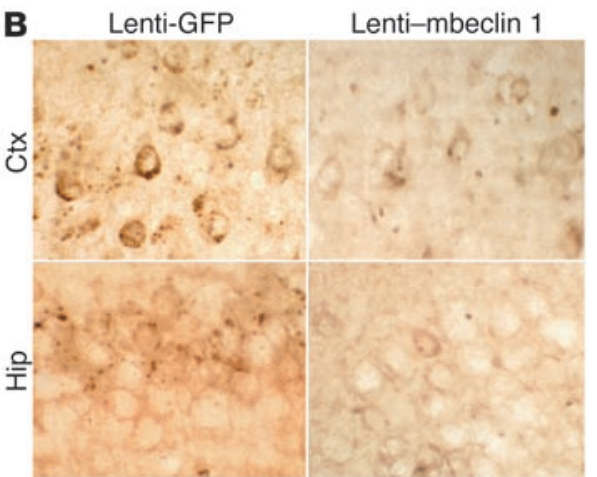

C

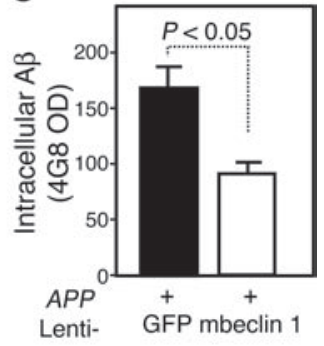

Lenti-

\section{Figure 7}

Increasing beclin 1 expression reduces amyloid pathology. Lentivirus encoding for GFP or mouse beclin 1 (mbeclin 1) was injected into the left (GFP) or right (beclin 1) hippocampus and cortex of 6-month-old APP transgenic mice. (A) GFP and mouse beclin 1 expression 8 weeks after lentivirus injection into the hippocampus. (B and $\mathbf{C}$ ) Intracellular $A \beta$ (4G8) was reduced with mouse beclin 1 overexpression in the hippocampus (B) and frontoparietal cortex (B and $\mathbf{C}$ ) of 8-month-old mice. (D) Extracellular $\beta$-pleated $A \beta$ deposits measured by thioflavin $\mathrm{S}$ staining in the frontal cortex was also reduced by beclin 1 overexpression. Results were analyzed by unpaired Student's $t$ test ( $n=4$ per group). Values are mean \pm SEM. Original magnification, $\times 10(A) ; \times 40(B)$.

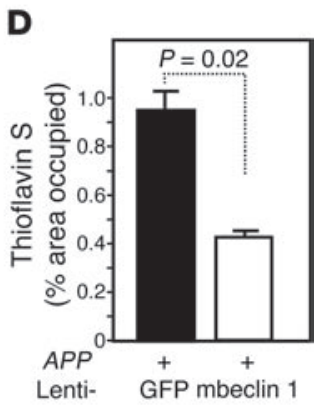

reduced in early stages of $\mathrm{AD}$ in affected brain regions. Because overexpression of beclin 1 can reduce $A \beta$ pathology in mice, restoring beclin 1 and autophagy may be novel approaches to treat AD.

\section{Methods}

Mice. The APP transgenic mice J20 (PDGF-hAPP695,751,770 V171F, KM670/671NL $_{\text {) }}$ and T41 (mThy-1-hAPP751 $1_{\mathrm{V} 171 \mathrm{I}, \mathrm{KM} 670 / 671 \mathrm{NL}}$ ) have been described previously $(29,30)$. Becn $1^{+/-}$mice (17) were crossed with heterozygous T41 transgenic mice or heterozygous CAG-GFP-LC3 transgenic mice (31). All lines were maintained on a C57BL/ 6 genetic background. Mice were anesthetized with $400 \mathrm{mg} / \mathrm{kg}$ chloral hydrate (Sigma-Aldrich) and transcardially perfused with $0.9 \%$ saline. Brains were dissected, and 1 hemibrain was fixed for $24 \mathrm{~h}$ in $4 \%$ paraformaldehyde and cryoprotected in $30 \%$ sucrose. Serial coronal sections $(30 \mu \mathrm{m})$ were cut with a freezing microtome (Leica) and stored in cryoprotective medium. The other hemibrain was dissected into hippocampus, neocortex, and remaining parts of the brain; tissues were weighed and frozen immediately at $-80^{\circ} \mathrm{C}$. All animal procedures were conducted with approval of the animal care and use committees of Stanford University and Palo Alto VA Medical Center.

Antibodies for immunobistochemistry and immunoblotting. The following antibodies were used: 3D6 (1 $\mu \mathrm{g} / \mathrm{ml}$; Elan Pharmaceuticals), biotinylated mouse monoclonal specific to human $A \beta_{1-5}$, biotinylated using EZ-link NHS Biotin (Pierce Biotechnology); 4G8 (diluted 1:500; Senetek), mouse monoclonal specific to human $A \beta_{17-24} ; 8$ E5 (Elan Pharmaceuticals), mouse monoclonal specific to human $\mathrm{APP}_{444-592}$; beclin (diluted 1:1,000, clone 20; BD Biosciences), mouse IgG2a monoclonal specific to human beclin $1_{171-291}$ (crossreacts with mouse and rat beclin 1); LC3 (diluted 1:1,000; Ab2389, generously provided by R. Kopito, Stanford University), rabbit polyclonal specific to N-terminal human LC3B; APP-CTF (diluted 1:1,000; generously provided by T. Golde, Mayo Clinic Jacksonville, Jacksonville, Florida, USA), rabbit polyclonal specific to the C-terminal of human APP; actin (A-5060; SigmaAldrich), rabbit polyclonal specific to actin; $\alpha$-tubulin (diluted 1:2,000;
Invitrogen), mouse monoclonal to bovine $\alpha$-tubulin; MAP-2 (Chemicon), mouse monoclonal specific to MAP-2; synaptophysin (Chemicon), mouse monoclonal specific to synaptophysin; CD68 (diluted 1:50, FA-11; Serotec); rat polyclonal specific to mouse CD68; Iba-1 (diluted 1:2,500; Wako Bioproducts), rabbit anti-Iba-1; NSE (diluted 1:200; Labvision), mouse monoclonal specific to human NSE.

Protein analysis. Proteins were extracted sequentially using $1 \times$ radioimmunoprecipitation assay (RIPA) buffer and $70 \%$ formic acid. Western blots were run as described previously (60). Multiple exposures were taken to select images with density within the dynamic range of the film. After development, films were scanned at $600 \mathrm{dpi}$, and band intensity was quantified using Metamorph software (version 6.1; Molecular Devices). Bands of interest were normalized to the corresponding actin, NSE, or $\alpha$-tubulin bands as indicated. For human and mouse data, most samples were run 3 times each, and mean values were determined for each sample to reduce experimental error. Multiple control samples were run on each gel to normalize across blots.

Histochemistry and immunohistochemistry. Investigators were blinded with respect to the genotype of the mice for all experiments. Coronal sections $(30 \mu \mathrm{m})$ at $360-\mu \mathrm{m}$ intervals through the hippocampus and frontal cortex ( $n=3-6$ per region) were stained using standard immunohistochemistry techniques. $A \beta$ and CD68 immunoreactivity were analyzed at $\times 4$ or $\times 10$ magnification on an Olympus IX71 microscope using Metamorph software, and the mean percent immunoreactive area was calculated per mouse. MAP-2 and synaptophysin are reliable indicators of synaptic and dendritic damage, respectively, and have previously been demonstrated to correlate well with loss of cognitive function in mouse models of neurodegeneration and in humans with $\mathrm{AD}(41,46,61,62)$; their relative abundance was measured as previously described $(46,63)$. Briefly, sections were immunostained with MAP-2 or synaptophysin primary antibodies followed by a secondary FITC-tagged anti-mouse IgG and analyzed with a laser scanning confocal microscope (BioRad). Digitized images were then 
analyzed with NIH Image version 1.63 (http://rsb.info.nih.gov/nih-image/) to determine the percent area of the neuropil occupied by MAP-2-immunoreactive dendrites or synaptophysin-immunoreactive presynaptic terminals. For calbindin quantification, digitized images of immunostained sections were obtained with a video camera mounted on a Zeiss microscope at a final magnification of $\times 30$ and then analyzed with Image ProPlus software (version 4.5.1; Media Cybernetics). For each mouse, 3 sections were selected, and from each section 3 random fields of 1,024 $\times 1,024$ pixels were analyzed. The total density of positive cells was averaged and expressed as normalized, corrected OD. For 4G8, sections were pretreated in $88 \%$ formic acid before incubation. Regions of intracellular or extracellular immunoreactivity were analyzed following the protocol used for calbindin. To assess the levels of $\beta$-pleated amyloid deposits in the APP mice, brain sections were stained with thioflavin $S$ as described previously (64). Briefly, 5-6 sections per mouse were air-dried on superfrost slides, stained with a $1 \%$ aqueous thioflavin $\mathrm{S}$ solution for $8 \mathrm{~min}$, and developed with several washes of ethanol and water. The area of thioflavin S fluorescent deposits was quantified using fluorescence microscopy and Metamorph software as described for $\mathrm{A} \beta$ and $\mathrm{CD} 68$.

Stereology. For stereological analysis, sections were analyzed with the optical dissector method as described previously (65). Briefly, 3 coronal sections $(30 \mu \mathrm{m})$ at systematic random intervals through layer II of the entorhinal cortex were stained with cresyl violet, and the number of nuclei in a $46.3 \times 31.5 \times 6 \mu \mathrm{m}$ dissector were counted. At least 100 nuclei were counted in 45 dissectors per mouse. From each genotype, 3 mice were selected at random, and 3 sets of counts from each mouse were averaged. Mean results are shown as total number per $\mathrm{mm}^{3}$.

$A \beta$ ELISA. ELISAs were performed as described previously (60) using antibody $266\left(5 \mu \mathrm{g} / \mathrm{ml}, A \beta_{13-28}\right.$; Elan Pharmaceuticals $)$ as the capture antibody for total $\mathrm{A} \beta$, or antibody $21 \mathrm{~F} 12\left(5 \mu \mathrm{g} / \mathrm{ml}, \mathrm{A} \beta_{37-42}\right.$; Elan Pharmaceuticals) as the capture antibody for $A \beta_{x-42}$ and biotinylated 3D6 $(2 \mu \mathrm{g} / \mathrm{ml}$, $\mathrm{A} \beta_{1-5}$; Elan Pharmaceuticals) as the detection antibody. After incubation with the secondary antibody, samples were incubated with avidin-HRP (diluted 1:4,000; Vector Laboratories), and the signal was developed using 1-step Turbo TMB ELISA solution (Pierce Biotechnology).

Neuron autophagy assay. Dissociated hippocampal neurons were prepared as described previously (66) from 1-day-old GFP-LC $3^{+} B e c n 1^{+/-}$and GFP$L C 3^{+} B e c n 1^{+/+}$mice (17) and cultured in neurobasal A medium (Invitrogen). After 10 days in culture, neurons were fixed with $4 \%$ paraformaldehyde, and GFP-LC3 staining was visualized using an Axioplan Zeiss microscope and $\times 100$ Plan Neofluar objective. The number of GFP-LC3 punctate dots per neuron was determined for 50 neurons per mouse for 3 mice per genotype.

Electron microscopy. Electron microscopy was performed as described previously (67). Briefly, perfused brains were fixed in $2 \%$ glutaraldehyde and $2 \%$ paraformaldehyde in 0.15 cacodylate buffer for $24 \mathrm{~h}$ at $4^{\circ} \mathrm{C}$. After fixation, brains were divided sagittally, and $0.2 \times 0.2 \mathrm{~cm}$ blocks were taken from the frontal cortex and hippocampal region of the right hemibrain for processing and embedding in epon. The epoxy-embedded blocks were sectioned with the Reichert Ultracut-E ultramicrotome (Leica), placed on 200-mesh copper grids, and stained in saturated ethanol/uranyl acetate and bismuth subnitrate. Sections ( $80 \mathrm{~nm}$ thick) were analyzed with a Zeiss EM10 Electron Microscope.

Beclin 1 lentivirus. Lentivirus expressing either mouse beclin 1 or GFP $\left(8.8 \times 10^{9}\right.$ transducing units $\left./ \mathrm{ml}\right)$ was generated as described previously (68). Virus was injected $(2 \mu \mathrm{l})$ into the frontal cortex and hippocampus of each mouse at 6 months of age. Lentivirus expressing mouse beclin 1 was injected into the right hemisphere, and lentivirus expressing GFP was injected into the left hemisphere as an internal control. Mice were sacrificed 8 weeks later and analyzed immunohistochemically.

Statistics. Data are presented as mean \pm SEM. Differences between and among groups were determined by ANOVA (with or without TukeyKramer post-hoc test or Dunnett's test) or unpaired Student's $t$ test, as indicated in the figure and table legends. A $P$ value less than 0.05 was considered significant.

\section{Acknowledgments}

We thank the Shiley-Marcos Alzheimer's Disease Research Center at UCSD, the Institute for Brain Aging and Dementia Tissue Repository at University of California, Irvine, and the Stanford Brain Bank at Stanford University for supplying the human brain tissue; N. Mizushima (Tokyo Metropolitan Institute of Medical Science, Tokyo, Japan) for providing GFP-LC3 mice; and M. Buckwalter and J. Luo (Stanford University) for critiquing this manuscript. This work was supported by NIH grants AG20603 (to T. Wyss-Coray), CA84254 (to B. Levine), and AG5131, AG18440, AG22074, AG10435, and AG02270 (to E. Masliah); by American Cancer Society grant RSG-98-339 (to B. Levine); by the John Douglas French Alzheimer's Foundation (to T. Wyss-Coray and F. Pickford); and by the Veterans Administration Geriatric Research, Education and Clinical Center (GRECC; to T. Wyss-Coray).

Received for publication August 13, 2007, and accepted in revised form April 2, 2008.

Address correspondence to: Tony Wyss-Coray, Department of Neurology and Neurological Sciences, Stanford University, SUMC Room A343, Stanford, California 94305-5235, USA. Phone: (650) 852-3220; Fax: (650) 849-0434; E-mail: twc@stanford.edu.
1. Hardy, J., and Selkoe, D.J. 2002. The amyloid hypothesis of Alzheimer's disease: progress and problems on the road to therapeutics. Science. 297:353-356.

2. Hardy, J. 1997. Amyloid, the presenilins and Alzheimer's disease. Trends Neurosci. 20:154-159.

3. Kopito, R.R. 2000. Aggresomes, inclusion bodies and protein aggregation. Trends Cell Biol. 10:524-530.

4. Ravikumar, B., and Rubinsztein, D.C. 2004. Can autophagy protect against neurodegeneration caused by aggregate-prone proteins? Neuroreport. 15:2443-2445.

5. Levine, B. 2005. Eating oneself and uninvited guests: autophagy-related pathways in cellular defense. Cell. 120:159-162.

6. Webb, J.L., Ravikumar, B., Atkins, J., Skepper, J.N., and Rubinsztein, D.C. 2003. Alpha-Synuclein is degraded by both autophagy and the proteasome. J. Biol. Chem. 278:25009-25013.

7. Ravikumar, B., et al. 2004. Inhibition of $\mathrm{mTOR}$ induces autophagy and reduces toxicity of poly- glutamine expansions in fly and mouse models of Huntington disease. Nat. Genet. 36:585-595.

8. Shibata, M., et al. 2006. Regulation of intracellular accumulation of mutant huntingtin by beclin 1 . J. Biol. Chem. 281:14474-14485.

9. Yu, W.H., et al. 2005. Macroautophagy--a novel \{beta\}-amyloid peptide-generating pathway activated in Alzheimer's disease. J. Cell Biol. 171:87-98.

10. Yu, W.H., et al. 2004. Autophagic vacuoles are enriched in amyloid precursor protein-secretase activities: implications for beta-amyloid peptide over-production and localization in Alzheimer's disease. Int. J. Biochem. Cell Biol. 36:2531-2540.

11. Hara, T., et al. 2006. Suppression of basal autophagy in neural cells causes neurodegenerative disease in mice. Nature. 441:885-889.

12. Komatsu, M., et al. 2006. Loss of autophagy in the central nervous system causes neurodegeneration in mice. Nature. 441:880-884.

13. Klionsky, D.J., and Emr, S.D. 2000. Autophagy as a regulated pathway of cellular degradation. Science. 290:1717-1721.

14. Berg, T.O., Fengsrud, M., Stromhaug, P.E., Berg, T., and Seglen, P.O. 1998. Isolation and characterization of rat liver amphisomes. Evidence for fusion of autophagosomes with both early and late endosomes. J. Biol. Chem. 273:21883-21892.

15. Eskelinen, E.-L. 2005. Maturation of autophagic vacuoles in mammalian cells. Autophagy. 1:1-10.

16. Liang, X.H., et al. 1999. Induction of autophagy and inhibition of tumorigenesis by beclin 1 . Nature. 402:672-676.

17. Qu, X., et al. 2003. Promotion of tumorigenesis by heterozygous disruption of the beclin 1 autophagy gene. J. Clin. Invest. 112:1809-1820.

18. Yue, Z., Jin, S., Yang, C., Levine, A.J., and Heintz, N. 2003. Beclin 1, an autophagy gene essential for early embryonic development, is a haploinsufficient tumor suppressor. Proc. Natl. Acad. Sci. U. S. A. 100:15077-15082. 
19. Yue, Z., et al. 2002. A novel protein complex linking the delta 2 glutamate receptor and autophagy: implications for neurodegeneration in lurcher mice. Neuron. 35:921-933.

20. Cao, Y., and Klionsky, D.J. 2007. Physiological functions of Atg6/Beclin 1: a unique autophagy-related protein. Cell Res. 17:839-849.

21. Zeng, X., Overmeyer, J.H., and Maltese, W.A. 2006. Functional specificity of the mammalian BeclinVps34 PI 3-kinase complex in macroautophagy versus endocytosis and lysosomal enzyme trafficking. J. Cell Sci. 119:259-270.

22. Liang, X.H., et al. 1998. Protection against fatal Sindbis virus encephalitis by beclin, a novel Bcl-2interacting protein. J. Virol. 72:8586-8596.

23. Chu, C.T., Zhu, J., and Dagda, R. 2007. Beclin 1independent pathway of damage-induced mitophagy and autophagic stress: implications for neurodegeneration and cell death. Autophagy. 3:663-666.

24. Allen Institute for Brain Science. 2004. Allen Brain Atlas. http://www.brain-map.org.

25. Petersen, R.C., et al. 2006. Neuropathologic features of amnestic mild cognitive impairment. Arch. Neurol. 63:665-672.

26. Diskin, T., et al. 2005. Closed head injury induces upregulation of Beclin 1 at the cortical site of injury. J. Neurotrauma. 22:750-762.

27. Pierce, A., and Small, S.A. 2004. Combining brain imaging with microarray: isolating molecules underlying the physiologic disorders of the brain. Neurochem. Res. 29:1145-1152.

28. Small, S.A., et al. 2005. Model-guided microarray implicates the retromer complex in Alzheimer's disease. Ann. Neurol. 58:909-919.

29. Mucke, L., et al. 2000. High-level neuronal expression of $A \beta_{1-42}$ in wild-type human amyloid protein precursor transgenic mice: Synaptotoxicity without plaque formation. J. Neurosci. 20:4050-4058.

30. Rockenstein, E., Mallory, M., Mante, M., Sisk, A., and Masliaha, E. 2001. Early formation of mature amyloid-beta protein deposits in a mutant APP transgenic model depends on levels of Abeta(1-42). J. Neurosci. Res. 66:573-582.

31. Mizushima, N., et al. 2004. In vivo analysis of autophagy in response to nutrient starvation using transgenic mice expressing a fluorescent autophagosome marker. Mol. Biol. Cell. 15:1101-1111.

32. Kabeya, Y., et al. 2000. LC3, a mammalian homologue of yeast Apg8p, is localized in autophagosome membranes after processing. EMBO J. 19:5720-5728.

33. Mizushima, N., and Yoshimori, T. 2007. How to interpret LC3 immunoblotting. Autophagy. 3:542-545.

34. Laferla, F.M., Green, K.N., and Oddo, S. 2007. Intracellular amyloid-beta in Alzheimer's disease. Nat. Rev. Neurosci. 8:499-509.

35. Nixon, R.A., et al. 2005. Extensive involvement of autophagy in Alzheimer disease: an immuno-electron microscopy study. J. Neuropathol. Exp. Neurol. 64:113-122.

36. de Villiers, W.J., and Smart, E.J. 1999. Macrophage scavenger receptors and foam cell formation. J. Leukoc. Biol. 66:740-746.

37. da Silva, R.P., and Gordon, S. 1999. Phagocytosis stimulates alternative glycosylation of macrosialin (mouse CD68), a macrophage-specific endosomal protein. Biochem. J. 338:687-694.

38. Counts, S.E., Nadeem, M., Lad, S.P., Wuu, J., and Mufson, E.J. 2006. Differential expression of synaptic proteins in the frontal and temporal cortex of elderly subjects with mild cognitive impairment. J. Neuropathol. Exp. Neurol. 65:592-601.

39. Heffernan, J.M., et al. 1998. Temporal cortex synaptophysin mRNA is reduced in Alzheimer's disease and is negatively correlated with the severity of dementia. Exp. Neurol. 150:235-239.

40. DeKosky, S.T., and Scheff, S.W. 1990. Synapse loss in frontal cortex biopsies in Alzheimer's disease: Correlation with cognitive severity. Ann. Neurol. 27:457-464.

41. Terry, R.D., et al. 1991. Physical basis of cognitive alterations in Alzheimer's disease: Synapse loss is the major correlate of cognitive impairment. Ann. Neurol. 30:572-580.

42. Masliah, E., et al. 2001. Altered expression of synaptic proteins occurs early during progression of Alzheimer's disease. Neurology. 56:127-129.

43. Buttini, M., et al. 2002. Modulation of Alzheimerlike synaptic and cholinergic deficits in transgenic mice by human apolipoprotein $\mathrm{E}$ depends on isoform, aging, and overexpression of amyloid beta peptides but not on plaque formation. J. Neurosci. 22:10539-10548.

44. Lewen, A., Li, G.L., Olsson, Y., and Hillered, L. 1996. Changes in microtubule-associated protein 2 and amyloid precursor protein immunoreactivity following traumatic brain injury in rat: influence of MK-801 treatment. Brain Res. 719:161-171.

45. Galvan, V., et al. 2006. Reversal of Alzheimer's-like pathology and behavior in human APP transgenic mice by mutation of Asp664. Proc. Natl. Acad. Sci. U. S. A. 103:7130-7135.

46. Palop, J.J., et al. 2003. Neuronal depletion of calcium-dependent proteins in the dentate gyrus is tightly linked to Alzheimer's disease-related cognitive deficits. Proc. Natl. Acad. Sci. U. S. A. 100:9572-9577.

47. Irizarry, M.C., et al. 1997. Abeta deposition is associated with neuropil changes, but not with overt neuronal loss in the human amyloid precursor protein V717F (PDAPP) transgenic mouse. J. Newrosci. 17:7053-7059.

48. Cataldo, A.M., and Nixon, R.A. 1990. Enzymatically active lysosomal proteases are associated with amyloid deposits in Alzheimer brain. Proc. Natl. Acad. Sci. U. S. A. 87:3861-3865.

49. Pattingre, S., et al. 2005. Bcl-2 antiapoptotic proteins inhibit Beclin 1-dependent autophagy. Cell. 122:927-939.

50. Furuya, N., Yu, J., Byfield, M., Pattingre, S., and Levine, B. 2005. The evolutionarily conserved domain of Beclin 1 is required for Vps34 binding, autophagy and tumor suppressor function. Autophagy. 1:46-72.

51. Liang, C., et al. 2006. Autophagic and tumour suppressor activity of a novel Beclin1-binding protein UVRAG. Nat. Cell Biol. 8:688-699.

52. Mandelkow, E.M., Stamer, K., Vogel, R., Thies, E., and Mandelkow, E. 2003. Clogging of axons by tau, inhibition of axonal traffic and starvation of synapses. Neurobiol. Aging. 24:1079-1085.

53. Gunawardena, S., and Goldstein, L.S.B. 2001. Disruption of axonal transport and neuronal viability by amyloid precursor protein mutations in Drosophila. Neuron. 32:389-401.

54. Ravikumar, B., et al. 2005. Dynein mutations impair autophagic clearance of aggregate-prone proteins. Nat. Genet. 37:771-776.

55. Esselens, C., et al. 2004. Presenilin 1 mediates the turnover of telencephalin in hippocampal neurons via an autophagic degradative pathway. J. Cell Biol. 166:1041-1054.

56. Wilson, C.A., et al. 2004. Degradative organelles containing mislocalized alpha-and beta-synuclein proliferate in presenilin-1 null neurons. J. Cell Biol. 165:335-346.

57. Nixon, R.A., Cataldo, A.M., and Mathews, P.M. 2000. The endosomal-lysosomal system of neurons in Alzheimer's disease pathogenesis: a review. Neurochem. Res. 25:1161-1172.

58. Kihara, A., Noda, T., Ishihara, N., and Ohsumi, Y. 2001. Two distinct Vps34 phosphatidylinositol 3-kinase complexes function in autophagy and carboxypeptidase Y sorting in Saccharomyces cerevisiae. J. Cell Biol. 152:519-530.

59. Vetrivel, K.S., and Thinakaran, G. 2006. Amyloidogenic processing of beta-amyloid precursor protein in intracellular compartments. Neurology. 66:S69-S73.

60. McGowan, E., et al. 2005. Abeta42 is essential for parenchymal and vascular amyloid deposition in mice. Neuron. 47:191-199.

61. Masliah, E., et al. 1992. Spectrum of human immunodeficiency virus-associated neocortical damage. Ann. Neurol. 32:321-329.

62. Buttini, M., et al. 1999. Expression of human apolipoprotein E3 or E4 in the brains of Apoe $e^{-/-}$ mice: isoform-specific effects on neurodegeneration. J. Neurosci. 19:4867-4880.

63. Brionne, T.C., Tesseur, I., Masliah, E., and WyssCoray, T. 2003. Loss of TGF-beta1 leads to increased neuronal cell death and microgliosis in mouse brain. Neuron. 40:1133-1145.

64. Wyss-Coray, T., et al. 1997. Amyloidogenic role of cytokine TGF- $\beta 1$ in transgenic mice and Alzheimer's disease. Nature. 389:603-606.

65. Everall, I.P., et al. 1999. Cortical synaptic density is reduced in mild to moderate human immunodeficiency virus neurocognitive disorder. HNRC Group. HIV Neurobehavioral Research Center. Brain Pathol. 9:209-217.

66. Kavalali, E.T., Klingauf, J., and Tsien, R.W. 1999. Activity-dependent regulation of synaptic clustering in a hippocampal culture system. Proc. Natl. Acad. Sci. U. S. A. 96:12893-12900.

67. Masliah, E., et al. 1996. Comparison of neurodegenerative pathology in transgenic mice overexpressing V717F $\beta$-amyloid precursor protein and Alzheimer's disease. J. Neurosci. 16:5795-5811.

68. Marr, R.A., et al. 2003. Neprilysin gene transfer reduces human amyloid pathology in transgenic mice. J. Neurosci. 23:1992-1996. 